\title{
Leucemia de células natural killer. Caso clínico
}

\author{
Mario Guerrero A, Pablo Lira V, Pablo Bertin C, \\ Mauricio Galleguillos Va, Mauricio Ocqueteau T. \\ Natural killer cell leukemia. \\ Case report
}

Natural killer leukemia is a rare and highly aggressive neoplasm, is more common in young male patients and has a very poor prognosis, with a median survival of few weeks. We report a 17 years old male patient who developed, after an acute upper respiratory disease, a rapidly multiorganic failure with pancytopenia. Bone marrow aspiration and trephine biopsy showed an acute lymphoblastic leukemia. The immunophenotype and immunohistochemistry revealed a natural killer acute leukemia. The disease progressed rapidly and the patient died shortly after the diagnosis (Rev Méd Chile 2005; 133: 457-60).

(Key Words: Killer cells, natural; Leukemia, lymphoblastic; Pancytopenia)

Recibido el 2 de noviembre, 2004. Aceptado el 16 de diciembre, 2004.

Departamento de Hematología-Oncología, Pontificia Universidad Católica de Chile. Santiago de Chile.

aTecnólogo Médico

L as neoplasias de células natural killer (NK) son entidades poco frecuentes, con una marcada tendencia a afectar la línea media, especialmente las regiones nasal y paranasal. Desde el punto de vista histológico, desarrollan un patrón de crecimiento angiocéntrico, con necrosis en más de $60 \%$ de los casos. Su principal incidencia se concentra en países de Asia Oriental y América del Sur, donde se ha correlacionado estrechamente con la infección por el virus de Epstein Barr (VEB) ${ }^{1}$.

La leucemia NK tiende a afectar principalmente a pacientes jóvenes, con un curso clínico

Correspondencia a: Dr. Mario Guerrero. Departamento de Hematología-Oncología, Pontificia Universidad Católica de Chile. Lira 85, Santiago, Chile. Fono: 56-2-3543092. Fax: 562-6332544. E mail: mariogacu@hotmail.com extremadamente agresivo. La sobrevida en estos casos es sólo de semanas, desarrollándose rápidamente neutropenia y falla multiorgánica. La afección del sistema nervioso central también es muy frecuente. El frotis sanguíneo y médula ósea muestran blastos medianos a grandes con gruesos gránulos en el citoplasma, situación que debe diferenciarse de la leucemia granular de células grandes, cuyo curso indolente y pronóstico difieren absolutamente ${ }^{2}$.

Desde el punto de vista fenotípico, se caracterizan por no expresar CD3 en superficie ni en citoplasma, presentar positividad para CD56 y no presentar reordenamiento del gen de TCR. Con gran frecuencia es posible demostrar la integración de secuencias genómicas del $\mathrm{VEB}^{3}$. Las alteraciones citogenéticas involucradas han sido aún escasamente caracterizadas, informándose de- 
leciones en los cromosomas 6q, 11q, 13q y 174,5, que han sido asociadas a la iniciación y progresión en el proceso oncogénico. El tratamiento agresivo con quimioterapia y profilaxis del sistema nervioso central (SNC) ha mostrado pobres resultados. Recientemente se ha publicado el caso de un paciente con 24 meses de sobrevida libre de enfermedad, tratado en forma agresiva con trasplante alogénico de médula ósea ${ }^{6}$.

\section{Caso Cúnico}

Paciente de sexo masculino, 17 años, sin antecedentes mórbidos de relevancia, que dos meses antes de su ingreso inició cuadro respiratorio alto caracterizado por disfonía, odinofagia, congestión nasal, calofríos y sensación febril nocturna no cuantificada. Recibió en forma ambulatoria distintos tratamientos antibióticos, sin mejoría clínica. Se realizó tomografía axial computada (TAC) de senos paranasales que mostró pansinusitis y nasofibroscopia que informó "laringitis costrosa", indicándose antibióticos y corticoides orales e inhalatorios.

Evolucionó febril con temperatura de $39^{\circ} \mathrm{C}$ y estridor laríngeo, motivo por el cual consultó al Servicio de Urgencia, donde se decidió su hospitalización.

Fue evaluado por otorrinolaringólogo, realizándose nueva endoscopia, que evidenció una lesión glótica costrosa con disminución del calibre del lumen laríngeo. El hemograma de ingreso mostró hematocito 40\%, Hb 13,5, leucocitos 4.700
RAN 2.700, plaquetas normales, velocidad de sedimentación de $20 \mathrm{~mm}$.

Se inició tratamiento antibiótico, corticoides y nebulizaciones con mejoría de los síntomas respiratorios y remisión de la fiebre. Siete días después se realizó nuevo control endoscópico, que mostró disminución de las lesiones costrosas con aparición de nuevas lesiones de aspecto granulomatoso. Dado estos hallazgos, se decidió efectuar biopsia y toma de cultivos en pabellón bajo laringoscopia directa. En el intraoperatorio, el paciente presentó hemorragia profusa y fiebre. Los exámenes tomados en pabellón mostraron Hcto de $37 \%$, leucocitos de 900 y 74.000 plaquetas.

Fue trasladado a la UCI quirúrgica donde desarrolló rápidamente insuficiencia respiratoria, requiriendo ventilación mecánica.

En ese momento, dada la aparición de pancitopenia, fue evaluado por hematología, efectuándose biopsia de médula ósea, aspirado para mielograma y citometría de flujo.

En las $48 \mathrm{~h}$ siguientes, el paciente desarrolló en forma rápidamente progresiva falla orgánica múltiple con compromiso respiratorio, renal y coagulopatía, asociado a shock refractario a drogas vasoactivas y cobertura antibiótica y antifúngica de amplio espectro, requiriendo soporte ventilatorio, dialítico y de hemoderivados.

La citología de médula ósea mostró $68 \%$ de blastos medianos a grandes con gruesos gránulos en citoplasma (Figura 1), mientras que la citometría de flujo reveló $22 \%$ de células NK

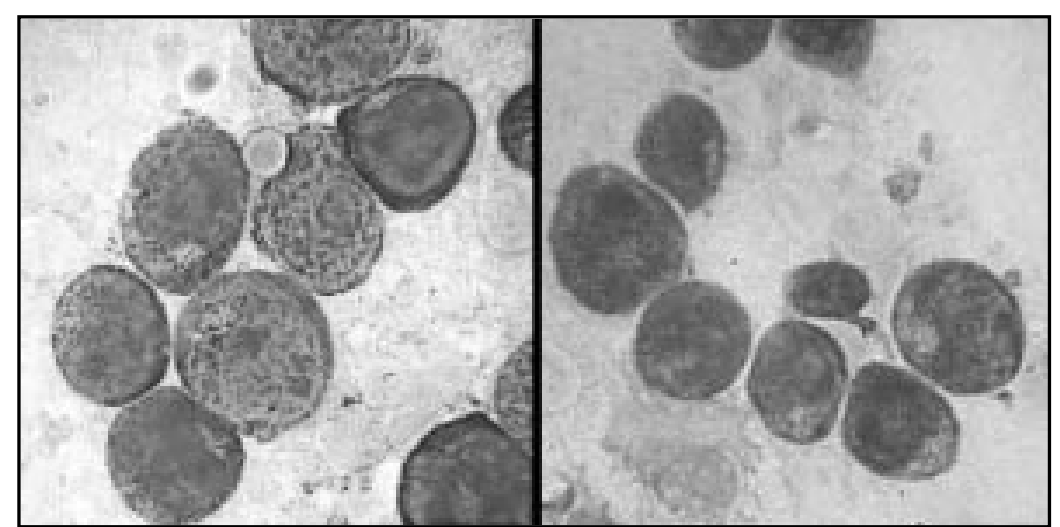

Figura 1. Examen citológico de médula ósea que muestra blastos de tamaño mediano a grande con gruesos gránulos en citoplasma. 


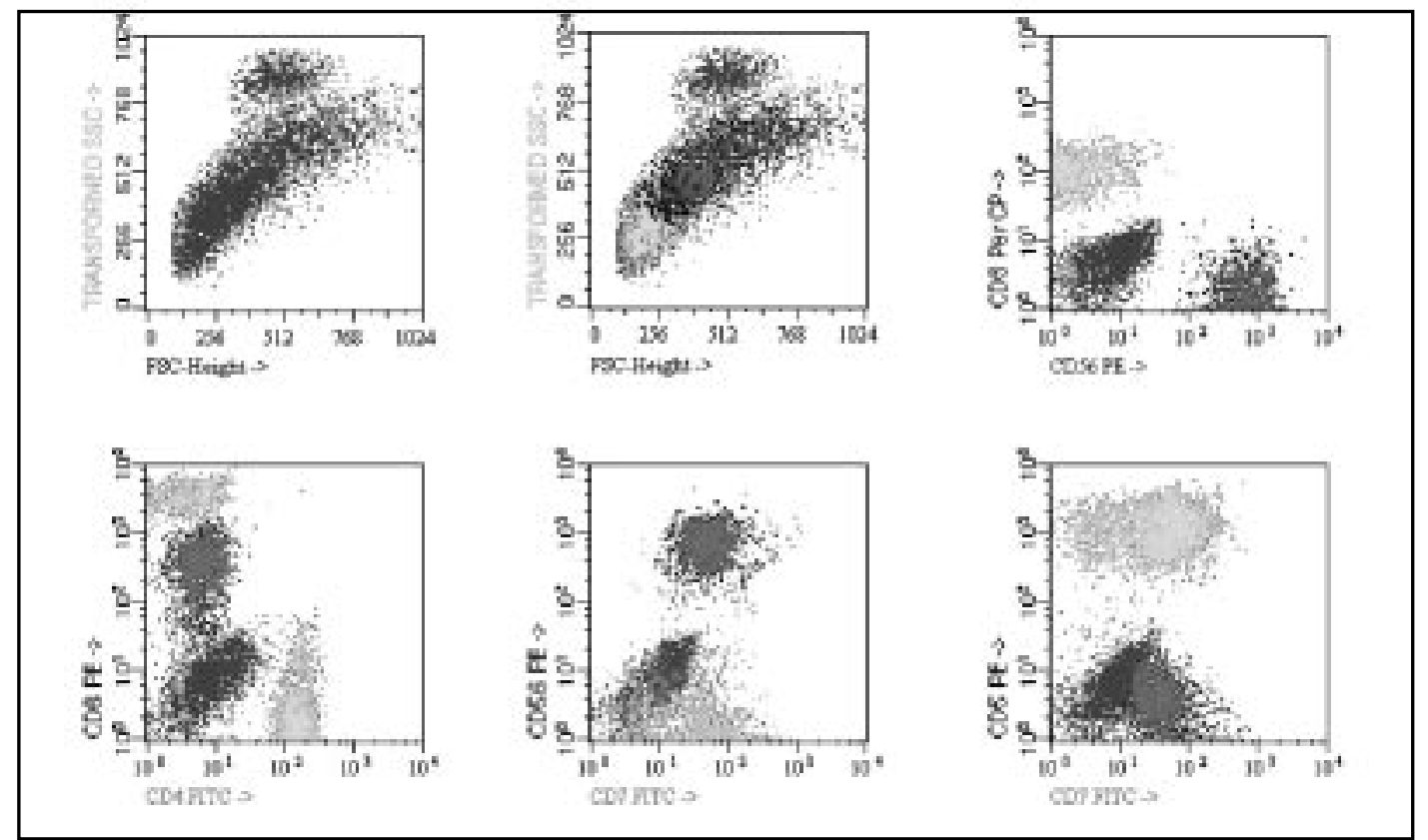

Figura 2. Inmunofenotipo por citometría de flujo que muestra la población de células natural killer patológica (CD56+, CD7+, CD8+, CD3-).

con patrón de dispersión de luz anormalmente elevado, expresión intensa de CD56, moderada de CD7 intracitoplasmático y de membrana, CD8 y CD45 intenso, en ausencia de CD3 en citoplasma y membrana y CD16. Los linfocitos B y $\mathrm{T}$ fueron inmunofenotípicamente normales (Figura 2).

Las tomografías computarizadas de tórax, abdomen y pelvis no mostraron compromiso nodal ni en la línea media más caudal.

La biopsia de la lesión glótica efectuada en pabellón, bajo laringoscopia directa, mostró solamente tejido necrótico. El informe anatomopatológico de la médula ósea mostró infiltración difusa por células grandes de tipo NK (CD56 intensamente positivo por inmunohistoquímica).

Dada la naturaleza de estos hallazgos y la extrema gravedad del cuadro, se iniciaron inmediatamente pulsos de metilprednisolona en dosis de $1 \mathrm{gr}$ al día y profilaxis de lisis tumoral, sin obtenerse respuesta. Setenta y dos horas después el paciente falleció por falla orgánica múltiple catastrófica absolutamente refractaria.

\section{Discusión}

Los linfomas NK representan un grupo de neoplasias de curso extremadamente agresivo, con características inmunofenotípicas propias: $\mathrm{CD} 2+, \mathrm{CD} 3$ en citoplasma-, CD3 sup-, CD56+, TCR-, además de presentar una asociación con la infección por virus de Epstein Barr entre 80 y 100\%7. La mayoría de los casos compromete la región nasal, paranasal o línea media, por lo que se les ha denominado granuloma letal de la línea media o linfomas T/ NK extranodales, variedad nasal de acuerdo a la clasificación de la $\mathrm{WHO}^{8}$.

La forma blástica de estos tumores es aún más infrecuente y más agresiva con un pronóstico extremadamente sombrío y sobrevida de semanas a pocos meses.

Dada la escasa incidencia de esta variedad de linfomas, la información disponible en la literatura en la actualidad se limita a reportes de casos clínicos y tratamientos empíricos basados en la alta agresividad de estos tumores, a falta de ensayos controlados y aleatorizados ${ }^{9}$. 
Un análisis retrospectivo de este caso clínico, ilustra prácticamente todas las características descritas en la literatura en este grupo de neoplasias.

La forma leucémica de los linfomas NK afecta principalmente a personas jóvenes, con predominio de sexo masculino, siendo Sudamérica una región de mayor prevalencia.

El inicio del cuadro clínico con síntomas respiratorios altos inespecíficos y posteriormente la evolución prácticamente fulminante a la falla orgánica múltiple refractaria está descrita prácticamente en todos los pacientes comunicados en la literatura ${ }^{10}$.

La angiocentricidad con tendencia importante a la necrosis que exhiben estos tumores, explica muy probablemente, el hallazgo histológico en la biopsia de la región glótica que precedió al rápido empeoramiento del paciente, siendo el estudio de

\section{REFERENCIAS}

1. Oshimi K. Leukemia and lymphoma of natural killer lineage cells. Int J Hematol 2003; 78: 18-23.

2. SoKol L, Loughran TP JR. Large granular lymphocyte leukemia and natural killer cell leukemia/ lymphomas. Current Treat Options Oncol 2003; 4: 289-96.

3. Kanavaros P, Lescs MC, Briere J, Divine M, Galateau F, JoAB I ET AL. Nasal T-cell lymphoma: A clinicopathologic entity associates with peculiar phenotype and with Epstein-Barr virus. Blood 1993; 81: 2688-95.

4. Siu LL, Chan JK, Wong KF, Kwong YL. Specific Patterns of Gene Methylation in Natural Killer Cell Lymphomas. Am J Pathol 2002; 160: 59-66.

5. Martínez LQ, Kremer M, Séluer G, Nathrath M, Domínguez A, Meneses A et al. p53 Mutations in Nasal Natural Killer/T-Cell Lymphoma from Mexico. Association with Large Cell Morphology and Advanced Disease. Am J Pathol 2001; 159: 2095105.

6. Ebihara $\mathrm{Y}$, Manabe A, Tanaka R, Yoshimasu $T$, ISHIKAWA $\mathrm{K}$, ISEKI $\mathrm{T}$ ET AL. Successful treatment of natural killer (NK) cell leukemia following a long- la médula ósea el que permitió establecer el diagnóstico.

El hallazgo morfológico en el mielograma de blastos de tamaño mediano a grande con escasos y gruesos gránulos en el citoplasma, hace recordar a la leucemia de células grandes granulares, derivada de células NK más maduras, pero con un curso clínico absolutamente distinto, ya que esta entidad tiene una sobrevida media que puede llegar a los 10 años ${ }^{11}$.

El curso extremadamente agresivo de los linfomas NK leucemizados y el rápido compromiso multisistémico, tal como ocumió en este paciente, impiden muchas veces el inicio de quimioterapia agresiva. Los reportes de casos en la literatura muestran que menos de $5 \%$ de los linfomas NK blásticos son diagnosticados en estadios precoces, todo lo cual resulta en una letalidad de, prácticamente, $100 \%$. standing chronic active Epstein-Barr virus (CAE$\mathrm{BV}$ ) infection with allogeneic bone marrow transplantation. Bone Marrow Transplant 2003; 31: 1169-71.

7. Lei KI, Chan LY, Chan WY, Johnson PJ, Lo YM. Diagnostic and Prognostic Implications of Circulating Cell-free Epstein-Barr Virus DNA in Natural Killer/T-Cell Lymphoma. Clinical Cancer Research 2002; 8: 29-34.

8. Cheung MM, Chan JK, Wong KF. Natural killer cell neoplams: a distinctive group of highly aggressive lymphoma/leukemias. Semin Hematol 2003; 40: 221-32.

9. Cheung MM, Chan JK, Lau WH, Foo W, Chan PT, Cs NG, Rk NGan. Primary non-Hodgkin's lymphoma of the nose and nasopharynx: clinical features, tumor immunophenotype, and treatment outcome in 113 patients. Journal of Clinical Oncology 1998; 16: 70-7.

10. LANG R. Diagnosis and management of primary nasal lymphoma of T-cell or NK-cell origin. Clin Lymphoma 2000; 1: 33-7; discussion 38.

11. Lamy T, Loughran TP JR. Clinical feature of large granular lymphocyte leukemia. Semin Hematol 2003; 40: 185-95. 